\title{
The Influence of Wechat On the Language Literacy of English Learners: How Does It Work?
}

\author{
Yan Dong* \\ School of Foreign Language Education \\ Zhuhai College of Jilin University \\ Zhuhai, Guangdong Province, China
}

\begin{abstract}
For most of the College English learners, the popularity of Wechat not only influences their socialization, but also affects their language literacy. By a survey and data analysis, the effects of influencing factors are classified and some suggestions are proposed in this paper. Wechat has an impact on their language literacy in three aspects: the micro-learning style, the choice of vocabulary and the self-regulated learning abilities. To make the micro-learning more effective, college English learners should develop a strong sense of information awareness, set clear and attainable micro-learning goals, reflect on the learning tasks and combine micro-learning with the evaluation of self-study achievement, and improve language literacy by more reading tasks and practice.
\end{abstract}

Keywords-language literacy; micro-learning; Wechat; influence

\section{MiCRO-LEARNING AND LANGUAGE LITERACY}

Learning is an activity influenced by many factors. With the popularity of smart phones, the influence of micro-learning cannot be ignored. Micro-learning is different from traditional learning in that the former is based on smart phone, features "fragmentation": learning anytime, anywhere. As a new way of micro-learning, the Wechat has become an indispensable part in college students' life in China, and it is also a great challenge to college students for it changes their way of learning and influence their language literacy.

As early as 1997, Mr. Tao Benyi, with the theme of "Chinese language education and language literacy", especially discussed the importance of language literacy In Chinese language education. According to him, "Language literacy" refers to the comprehensive reflection of several factors such as learning and communicative ability, creativity and self-development in human cognition, emotion and operation, which are conveyed by language and Chinese characters. Since then, the connotation and manifestation of the term "language literacy" have been discussed by many domestic scholars and educators. (Jiu Yumei, 2007; Xuanling, 2013) ${ }^{[2][3]}$

College students are supposed to be advanced native language speakers, such as being able to quickly understand what others are talking about, expressing their ideas appropriately, reading books of and out of their major, and writing in a variety of styles. However, a phenomenon that cannot be ignored is that many college students do not possess these qualities, and some investigations also show that the

Sponsored by the The "13th Five-Year- plan" of philosophy and Socia Sciences in Guangdong Province: A Study on mixed flipped classroom teaching mode based on U-Campus and Wechat (GD18WXZ05) language literacy of contemporary college students is not as good as it is expected (Liu Meijuan 2005, Lin Zhiya, Hu Haoyu, 2012$)^{[4][5]}$. Language ability is also related to thinking abilities. College students who are undertaking higher education should have logical thinking, critical thinking, creative thinking and other thinking qualities. However, studies show that a large number of college students lack critical thinking abilities.(Huang Yuanshen, 2010; Johnston, B., Mitchell, R., Myles, F.,2011) ${ }^{[6][7]}$

According to the 43nd report, the China Internet Information Center (CNNIC) released in Beijing, until December 30th, 2018, the number of Internet users in China has reached 829 million, with an internet penetration rate of $59.6 \%$. The number of mobile phone users has reached 817 million, and the proportion of Internet users who use mobile phones to surf the Internet has reached 98.6\%. Surfing the Internet with mobile phones has become a major way of surfing online. To some extent, communication between people can also be said to be a way of micro-learning activity. Therefore, it is very important to investigate the present situation of micro-learning of college students, to identify the problems and to put forward strategies, so that the college students can make better use of this new learning method and adapt to their social life better.

\section{HOW WECHAT INFLUENCES THE LEARNERS’ LANGUAGE LITERACY}

In order to know more about the influence of Wechat, a questionnaire on the influence of Wechat was distributed among college English learners. Those learners (participants) are from an Independent College in South China, of medium English level, and many are typically lack of autonomous learning ability and critical thinking abilities. However, they are more interested in a new form of learning and very active in social practice. As a result, 1152 effective questionnaires were collected. The questionnaire focuses on the influencing factors of Wechat on college English learners' language literacy. According to the data, Wehcat, as a new form of microlearning, influences these college English learners' language literacy in the following aspects: their micro-learning style, their choice of vocabulary and their self-regulated learning abilities.

A. How Wechat influences English learners' micro-learning style

The influence of Wechat on students' learning style is based on the following two reasons: Firstly, the study via 
Wechat is a new way of micro-learning which comes into being with the modernization and informationization of society. Compared with the traditional learning mode, micro-learning has its unique characteristics. Such as " $4 A$ " (Anyone, Anytime, Anywhere, Any device), personalization and other interesting characteristics. Secondly, If college students want to improve their overall quality and competence, it is far from enough that they only depend on learning in classrooms. Instead, they should make full use of their "fragment" time to carry out their personalized learning with the help of modern devices.

According to the data collected in the questionnaire, $51.13 \%$ learners have added 2 to 3 Wechat subscriptions. Most of them (73.96\% and 87.5\%) expect to practice oral English or communicate with foreign native English speakers. $90.19 \%$ of them admit that the main advantage of micro-learning through Wechat is its accessibility and $66.32 \%$ is considering making plans of learning.

The data indicates that the Wechat are changing their micro-learning style. More than half of college English learners are paying attention to micro-learning, and most of them claimed that they have the initiatives to learn. It seemed that they depend too much on native English teachers. However, due to the lack of native English teachers in classroom teaching, they do not have much face-to-face communication opportunities with native speakers. It is also clear that they need much guidance on learning strategies.

Reading English articles in the Wechat subscriptions has become a new way of acquiring knowledge and improves English. But the fact is most of them can't learn systematically. The micro-learning via Wechat is more like a hobby or a leisure activity in their spare time.

\section{B. How Wechat influences English learners' choice of vocabulary}

The influence of Wechat on English learners' choice of vocabulary is mainly reflected in the impact of internet catchwords on their language literacy. Compared with traditional vocabulary, internet catchwords feature more diverse, fresh, chic, and humorous. Network catchwords enriched the language literacy of college students. The characteristics of the rejuvenation of the main body of netizens make the network catchwords full of vitality.

The positive effects of internet catchwords on college students' language can be shown in their choice of daily vocabulary and language expressions. Firstly, internet catchwords enrich the daily vocabulary of college students. For example, the title “亲 (dear)” is initially used for greeting and addressing online customers, but now it is popularly used in addressing friends and other acquaintances. This kind of online language has become an important word for Wechat communication among young netizens nowadays. According to the sixth edition of the Modern Chinese dictionary, published in 2012, a number of online catchwords have been included, such as "Microblog”, "Moonlight clan", "group purchase”, "otaku male" and so on. The network vocabulary becomes prevalent quickly, but usually last for a short time. Secondly, the popularity of internet catchwords means more frequent cultural communication. The collisions between Chinese and
English cultures naturally create more fresh online languages, such as “ $\square$ 豆(Ai Dou)” is the Chinese translation of "idol”. The expression that can most embody cultural exchange integration should be "no zuo no die", which originates from Chinese, meaning "if you do not do evil, you will not die".

Meanwhile, the negative effects of internet catchwords are also demonstrated in young learners' choice of vocabulary. The timeliness, symbolization and fragmentation of the network catchphrase destroy the users' ability to read and think in depth. Network catchwords usually disappeared quickly before they can precipitate into the main culture. In Syntax, the free and irregular expression of network catchphrase makes them not conform to the logic and aesthetics of language expression. With emoticons, pictures or symbols, some network catchwords are too simplistic and too obscure to be understood, thus influence the standard language use by college students.

\section{How Wechat influences English learners' self-regulated learning abilities}

In the micro-learning based on Wechat, learners' language literacy are also influenced by factors like learning motivation, learning plan, the ability to screen information, the ability to control the progress of learning, the ability to analyze and think, and the self-regulated learning abilities. These factors are closely related to learners' micro-learning efficiency, hence affecting the learning effect. Among them, self-regulated learning ability, that is, "how to regulate the degree of microlearning” is very important. Generally speaking, people are often obsessed with the characteristics of micro-learning, and usually misunderstand the "degree of micro-learning." They often overlook the much time they spend on their smart phones before they regretted about it. The word "Phubbing" refers a phenomenon that people are too much involved in the use of mobile phones, including entertainment games, learning and so on.

According to the recent survey, about $33.16 \%$ participants in the questionnaire respond that they only read the Wechat subscriptions to kill time. About $81.6 \%$ college students spend less than 20 minutes every day learning English through Wechat subscriptions. But $64.41 \%$ of them agree that microlearning is useful for them to make good use of the "fragment" time and accumulate knowledge. The results clearly reveal that Wechat does have a great influence on students' self-regulated learning abilities as well as their learning styles.

Their attitudes towards micro-learning with Wechat are shown in the following Chart (Fig. 1):

\section{How do you regard Wechat as a new way of Micro-learning?}

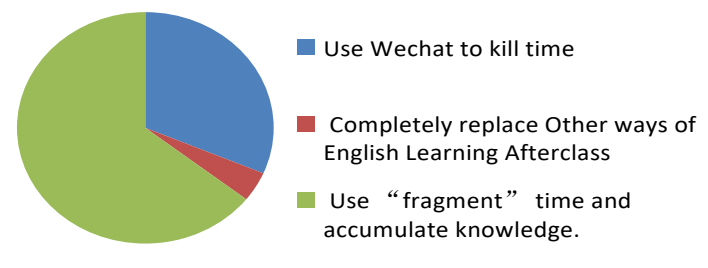

Fig. 1 College students' learning attitudes to Micro-Learning with Wechat 
By a further look, it can be seen that micro-learning is closely related to the autonomous learning. The learning process completely takes place in their spare time, without any pressure of passing examinations or undertaking evaluations. This "freedom" usually leads to leaning without plan, or without the evaluation of the effectiveness. If learners lack the self-regulated learning abilities, they are easily distracted by other irrelevant information. For example, they may start with learning new words via some kind of App, but end up with shopping online.

\section{SUGGESTIONS FOR USING WECHAT TO IMPROVE LANGUAGE LITERACY}

According to the results of the questionnaire and interviews, it is found that there are still some misunderstandings about micro-learning based on Wechat, learners need to reflect on their own learning behavior, find out the existing problems, and improve not only the efficiency of micro-learning but also the language literacy. Therefore, this paper puts forward some suggestions on how to improve learners' language literacy as well as micro-learning efficiency.

\section{A. Develop a strong sense of information awareness.}

Information awareness means the process of dealing with information from one's own point of view, including the demand, judgments, access, absorption, use of information, and so on. Various factors of information consciousness (tendency, strength or weakness) directly affect learners' acquisition and utilization of information. In daily life, learners are faced with huge amount of information. The information should be rationally screened, processed and utilized. College students should be fully aware of what specific information they need and thus intuitively learn some information index skills or read more information management books.

With abundant online information, learners need to bear in mind that some information is useless or unbelievable. They should be aware of what information is useful for them so that they can keep themselves on track. Another suggestion is they should be fully aware of their English level and learning the background, so that they can get access to useful learning resources that fit in their language proficiency and thus make the learning more effective.

\section{B. Set clear and attainable micro-learning goals.}

Set a certain period of time every day to complete the language learning tasks. The learning goal is instructive to learning activities and directly influences the result of learning. Clear and attainable micro-learning goals make learners start learning with aims and not easily be distracted by other unrelated information, hence producing more sense of achievement once they can reach the goals. College students should be aware that micro-learning by Whchat is not always improvisational and aimless. As long as there are learning activities, they need to set certain goals, no matter they are starting one-on-one interaction or searching language learning resources with the help of Wechat "Moments" or another learning platform.

\section{Reflect on the learning tasks with the help of Wechat}

After completing the corresponding language learning tasks, in order to make it more efficient and relevant to other knowledge, Students should participate into some task reflection activities, such as "Self-questioning method". When the learning process is interrupted or distracted, the learners can ask themselves "What am I doing?" "Have I finished the tasks?" and so on, to remind themselves to keep on the track all the time. Another useful method is "Self-analysis method": Analyze their own learning behavior, find out the existing problems, clarify their own behavioral defects, and give themselves reasonable hints. For example, learners are supervised to make written or oral reports after completing their language learning tasks, or are divided into several groups and ask each group to have discussions, etc. In this way, students can know their own language learning deficiencies, and actively correct them, so that students can learn the target languages more effectively.

\section{Combine micro-learning with the evaluation of self-study achievement.}

According to some researchers, there is no complete learning system about micro-learning, especially in the field of micro-learning design and evaluation (Zhang, 2013) ${ }^{[8]}$. Therefore, more functions about collecting feedback from students or about learning-to-testing activities should be included in Wechat learning platforms. Students need to provide timely feedback, to develop the habit of combing and summarizing knowledge information, to pay close attention to the scientific research trends, and then to record their learning achievements on micro-blogs and blogs, which will encourage learners to further consolidate their knowledge and information.

In order to provide better learning resources to meet the current learners' needs, learning activities designers should pay more attention to the individual differences; provide different forms and learning activities in different levels. As to the evaluations, formative evaluation and summative evaluation should be comprehensively combined. Only in this way can the evaluations better promote learners' participation in microlearning and improve their sense of achievement.

\section{E. Improve language literacy by more reading tasks and practice}

Language learners’ overall language literacy and critical thinking abilities cannot be improved overnight. Even if the micro-learning with Wechat is successful, it is far from enough that the learners' language literacy be improved quickly by reading articles in the Wechat subscriptions. It is essential to strengthen cultural and linguistics education by setting up necessary classic reading courses and guide students to read cultural classics extensively. A large part of the reason why college students are not good at expression is that they lack the related input and training. Therefore, in order to improve language literacy and critical thinking skills, college students should read extensively, including reading a wide variety of books in the field of natural science and social science. Attending more relevant classes or select more relevant courses is also necessary for them to improve their language literacy. 
Some language learners' language literacy is interfered by their dialects or by the internet catchwords. In order to cultivate better language sense, it is necessary to eliminate the interference of catchwords and dialects, especially in academic language use. Besides, try to use standard expressions in daily life and online chatting. Making use of more opportunities to practice by participating in some speech contest or other social activities. More practice of language means more learning opportunities and better communication.

\section{CONCLUSION}

Although the application of micro-learning is increasing rapidly in the world, so far there are still a few excellent cases, especially in China (Zhang, 2013) ${ }^{[8]}$. The study mentioned in this paper is only a case study, may not be suitable for generalization in other situations. However, the results and the suggestions can be served as a reference for learners at the same English level. How to improve language literacy in autonomous learning based on micro-learning has become a problem for college English learners. Although the microlearning process is different from the traditional language learning in various ways, the application of the meaning of learning and the goals are consistent. Therefore, to improve language literacy, it is necessary for learners to improve their day-to-day learning styles, language choices, self-learning habits and so on. It is believed that with the continuous progress of computer network technology and multimedia technology, the autonomous English learning will be promoted more quickly with more new learning methods so that the overall language literacy of English learners will be constantly on the way of improvement.

\section{REFERENCES}

[1] Tao Benyi, Chinese language education and language literacy [J]. The Communication of Chinese Teaching 1997, 1: 2-4 (In Chinese)

[2] Ju Yumei, Reflections on the courses of linguistics for College English majors[J]. Foreign Languages and Their Teaching, 2007, No. 8:31-33 (In Chinese)

[3] Xuan Ling, Discussion on College Students' Language Literacy and Quality Education[J]. Language Planning, 2013,09: 76-77 (In Chinese)

[4] Liu Meijuan, Cultivate Opportunities for Practice and Language Literacy [J] . Journal of Language and Literature Studies. 2005,6:97-99 (In Chinese)

[5] Lin Zhiya, Hu Haoyu. The Present Situation of College Students' Language Literacy and the Strategies [J]. Read and Write Periodical. 2015,Vol. 9 No.5: 41-42 (In Chinese)

[6] Huang Yuanshen On the Reform of English Majors Courses-Further Discussion of the lack of Critical Thinking Abilities [J]. Foreign Language World, 2010, Vol 1: (In Chinese)

[7] Johnston, B., Mitchell, R., Myles, F., et a1.Developing Student Critical ability in Higher Education [M]. London: Continuum, 2011: 11.

[8] Zhang Zhenhong, Yang Qingying and Han Zhi, A Study on MicroLearning: Present and Future[J]. Chinese Education Technology, 2013,11, Vol 322: 12-20 (In Chinese) 